\title{
Analysis of Factors Enhancing Credit Utilization Among Lowly Endowed Women Farmers
}

\author{
James Obara* \\ Egerton University, Njoro, Kenya
}

\begin{abstract}
Credit is an important aspect in farming. The problem is the restricted accessibility to farm credit by the Lowly Endowed Women (LEW) farmers. The banks and other formal lending institutions consider LEW farmers a risk and/ or not credit worth. To be unveiled yet are the strategies and interventions that ought to be put in place so as to enhance credit use by Lowly Endowed Women farmers. The research was done on women farmers in Funyula Sub County, Busia County, Kenya. A sociological inquiry, in form of a survey was used to collected field data based on the views of the LEW farmers on the various credit arrangements to determine which ones were acceptable and could lead to both effective use of credit and high. In addition to the field survey, case studies were carried out for additional data and to strengthen the findings of the field survey. The target population was the women farmers. All the 15,000 households Funyula Sub County (Ministry of Agriculture, 1997) constituted the accessible population. The study assumed every household had a woman. For case studies, the study population was chosen from the on-going or immediate past rural programmes with an informal credit component for lowly endowed people, particularly the women. Sampling of the household was undertaken using a proportionate, stratified random sampling technique on sub locational basis. The sub county had 28 sub locations. All the Sub Locations were represented in the study. A sample of 210 LEW farmers was taken. For the case studies, agencies that had a credit component for the lowly endowed people were selected. Three credit programmes run by two agencies with fairly successful record of credit support to the poor were studied. These agencies included an NGO, Kenya Rural Enterprise Programme (K-REP) and a government/ bilateral donor assisted agency, the DANIDA which supported Kitui Agricultural Project (KAP). Field data was collected by the researcher. The Statistical Package for the Social Sciences (SPSS) was used to aid the analysis of the data. Chi-square was used to test the relationship between the variables. The level of significance for the relationship between variables was rejected or accepted at $\mathrm{p} \leq 0.05$ significant level. The findings of the study were: There is no significant relationship between conditional credit and effective use of credit. However, there is a positive relationship between unconditional credit but with strict supervision by the credit agency and effective use of credit. The result of relationship between pre-training and use of credit indicated is a positive relationship between pre-training and effectiveness of credit use. On credit in-kind, it was found to be positive relationship implying credit in-kind is put to effective use by the LEW farmers.
\end{abstract}

Keywords: Credit utilization, Lowly Endowed Women, Farmers

DOI: $10.7176 / \mathrm{JESD} / 11-4-08$

Publication date: February $29^{\text {th }} 2020$

\section{Introduction}

Credit is an important aspect in the fight against poverty. Khandker and Khalily, 1996 noted, Poverty alleviation and empowerment could be achieved by mobilizing target households and forming organizations, improving social awareness, enhancing income and productivity by providing credit, social education and skills development training It has been argued that improved seeds, fertilizers, insecticides, animal feeds, additional labour to family labour and other production support requirements are needed to maximize farm production (Lele, 1973; Zeller and Sharma, 1998). However, these inputs require finances which the LEW find difficult to get. In Bangladesh, under the Bangladesh Rural Advancement Committee's (BRAC) credit programmes, Programmes considered to have had some significant effect on poverty alleviation to the poor. Interventions that led to access and effective use of credit included building small groups through which individuals were trained and empowered technically and financially (Khandker and Khalily, 1996).

\section{Objectives of the Study}

The purpose of the study was to collect and analyze relevant data from the study area, Funyula Sub-County and elsewhere and make suggestions for improvement in the administration and management of Agricultural Extension and related credit-linked programmes to the disadvantaged groups such as the LEW with a view of enhancing effectiveness of use of credit by the LEW famers. The specific objective of the study was to determine factors affecting effectiveness of credit use by the LEW farmers in Busia County with respect to:

i. $\quad$ Credit offered with conditions.

ii. Credit offered without conditions attached, but with strict supervision on its use.

iii. Credit in-kind, rather than cash credit 
iv. Pre-training to credit offer peer monitoring by group members

\section{Hypothesis}

The objective of the study was translated into the following null hypothesis: There is no relationship between effective credit use and:

i. Credit offered with parallel arrangements specifying for example, for what purposes the credit shall be used.

ii. Credit offered without conditions attached to it but with strict supervision, that is the choice of project in which to invest the borrowed capital is left to the recipient but the lending agency ensures credit is strictly used for the intended purpose.

iii. $\quad$ Credit in-kind such as in form of farm inputs, machinery rather cash credit.

iv. Pre-training to enhance the productivity of the credit offered.

v. Peer monitoring, that is members of the group through which the credit was offered take active role to check on the use of the credit by the recipients

The study hypothesized that there is no relationship between credit offered under different lending arrangements namely: conditional credit, unconditional credit but with strict supervision, credit in kind,, pretraining , peer monitoring and use of the credit by Lowly Endowed Women farmers. The independent variables of the study were credit offering with conditions attached to it (offered with parallel arrangements specifying where and how the credit shall be used and credit offering without conditions but with strict supervision, that is the choice of project in which to invest the borrowed capital is left to the recipient but the lending agency ensures credit is strictly used for the intended purpose. The independent variables were measured by rating the responses of credit beneficiaries on a five point Likert Scale of SA $=$ Strongly Agree, $A=$ Agree, NS $=$ Not Sure, D = Disagree and SD $=$ Strongly Disagree. The farmers were asked to respond to a set of statements related to credit conditions of offering and subsequent credit use. The dependent variable was effective use of the credit offered and was measured in terms of number of borrowers using the credit effectively that is, for the intended purpose(s).

\section{Research Methodology}

The research was done on women farmers in Funyula Sub County, Busia county, Kenya. According to Ministry of Agriculture (1997), the sub county which had about 15,000 households was chosen because no similar research had been done there, and yet the land has high potential for farming activities. The average rainfall ranges from 1000 to $1400 \mathrm{~mm}$ per annum, with a $60 \%$ reliability and characterized mainly by warm and semi-humid climate, much suited for cotton growing (Jaetzold and Schmidt, 1982).

A field survey was carried out in Funyula Sub County. A sociological inquiry, in form of a survey was used to collected field data based on the views of the LEW on the various credit arrangements to determine which ones were acceptable and could lead to both effective use of credit and high credit repayment rate. In addition to the field survey, case studies were carried out for additional data and to strengthen the findings of the field survey as advocated by Casley and Lury (1981). Three case studies were carried out, one was a rural development programme with a credit component for the poor, administered by GoK/bilateral donor agency. The other two case studies were of credit programmes administered by an NGO that accessed credit to the rural community members. The credit programmes had different approaches in the way they were administered to the poor. The investigator visited the institutions, discussed with appropriate Officers in the head office followed by field visits, details are discussed elsewhere in the report.

The target population was the women farmers. All the 15,000 households in Funyula Sub County (Ministry of Agriculture, 1997) constituted the accessible population. For case studies, the population was chosen from the on-going or immediate past rural programmes with an informal credit component for lowly endowed people, particularly the women. Selection of programmes at the national level, rather than limiting to the local ones, was decided upon for comparison purposes.

Sampling of the household was undertaken using a proportionate, stratified random sampling technique on sub locational basis. All the sub locations were represented in the study. This was to ensure a wide representation of the target population. It was important to collect data and get the views across the sub-locations since they differ in population characteristics and sizes as suggested by Tuckman (1978), Moher and Kalton (1971). On average, four to ten respondents were drawn from each sub-location, with the variation in numbers dictated by the population size of farmers in each sub-location. The sampling frame was obtained from the records of the Ministry of Agriculture and Livestock Development Technical Assistants (TAs) manning the twenty five sub-locations in Funyula Division. The investigator met and explained the purpose of the study to the Sub County Extension Coordinator (SCAO), in charge of Funyula subcounty. This was followed by another meeting, which was arranged by the DEC for the investigator to meet the Technical Assistants (TAs). The meetings were to facilitate development of a sampling frame. Through the office of the Sub County Extension Coordinator (SCAO), each TA was asked to prepare a list of LEW households within the sub-location. A combined list of the households from 
the TAs formed the sampling frame from which the sample households for the study was selected. Consequently, a sample of $210 \mathrm{LEW}$ households was taken. For a study population of 15,000, a sample of 210 respondents was considered sufficient. The sample size of 210 respondents was above the minimum recommendation. Nassiuma, 2000; Kathuri and Pals, 1993 both indicate sample size from a study population could be obtained by applying the formula:

$$
\begin{aligned}
& \mathrm{n}=\frac{\mathrm{NC}^{2}}{\mathrm{C}^{2}+(\mathrm{N}-1) \mathrm{e}^{2}} \\
& \text { where } \mathrm{n}=\text { Sample size, } \mathrm{N}=\text { Population, being15,000), } \mathrm{C}=\text { Coefficient }
\end{aligned}
$$

of variation, 0.21 being lowest acceptable value, $\mathrm{e}=$ Standard error (0.02), lowest acceptable value.

Thus, $\mathrm{n}=$ $15,000 \times 0.2^{2}$

$$
0 . \overline{21^{2}+(15,000-1)\left(0.02^{2}\right)}=155
$$

For the case study, agencies that had a credit component for the lowly endowed people were selected. Three credit programmes run by two agencies with fairly successful record of credit support to the poor were studied. These agencies included an NGO, Kenya Rural Enterprise Programme (K-REP) and a government/ bilateral donor assisted agency, the DANIDA supported Kitui Agricultural Project (KAP). The choice of the two agencies was influenced by the secondary information that was available about the programmes and the fact that they had different approaches to accessing credit and to credit administration which provided the basis for comparison. Two credit programmes were chosen from the K-REP, while for the government/ bilateral donor-assisted programmes, DANIDA supported KAP was chosen over the SIDA supported National Agricultural and Livestock Extension Programme (NALEP). The DANIDA supported KAP was found to be most relevant for the study. The programmes had different approaches of providing access to credit to their target groups and also provided useful information for comparison purposes.

The instruments for the study were developed to address issues in the research objectives and provided data to answer the hypothesis. They included the questionnaire containing structured items for the field survey, and the questionnaire guide which was used for the case studies. A first draft questionnaire was developed and discussed with members of the Faculty of Education and Human Resources, including members of the Department of Agricultural Education and Extension, Egerton University, Njoro, soliciting expert opinion on its practicability and effectiveness. The questionnaire had two sections. Section one was composed of questions with items with alternative (multiple choice) responses to choose from. However, there were some items that were open ended and these were intended to provide the respondents with the freedom to respond to any reasonable details and extent on the issues raised. Section two of the questionnaire was composed of questions on a Likert scale intended to tap the attitudes and feelings of the respondents. The questionnaire was used to collect primary data on the following items: profiles of the respondents, avenues or structures for credit intervention, various credit arrangements in relation to response to credit, effective use of credit, credit repayment and the effect of credit on emergence of market-oriented farming. A pre-test for reliability of the instrument was done using twenty farmers in Njoro Sub County. Njoro Sub County was used for pre-testing because farmers in Njoro share some commonality on some of the elements that were being investigated in the study and secondly because of its convenience. Crownbanch coefficient alpha $(\alpha)$ was computed for estimation of the internal reliability of the questionnaire, which was found out to be 0.87 , indicating that the instrument was reliable. According to Borg and Gull (1983) a reliability level above 0.75 is acceptable. A questionnaire guide rather than a structured questionnaire was used in the case studies to collect information and data on issues of the programmes, and for interviewing the programme proponents and implementers. The items in the questionnaire guide were organizational arrangements required for credit offer, conditions of credit offer, recovery arrangements and effects of credit that was offered.

The investigator carried out the actual data collection. Where sampled respondents were never found, the closest neighbour was chosen as a replacement. The questionnaire items were read to the respondents in local vernacular language to solicit their responses. On the case studies a questionnaire guided by the questionnaire guide was used. The interview was followed by examination of the project documents including field evaluation reports which were supplied, providing the details being studied in the case study. A field visit to Funyula Financial Services Association (FSA) was arranged. Here arrangements were made and the board of governors, employees and a shareholder in the FSA were interviewed by the investigator. For the Kitui Agricultural Project (KAP), the investigator made a scheduled visit to Kitui District Headquarters, where arrangements were made to interview various officers directly involved in the implementation of the programme, the Project Coordinator, the Agriculturist, the Community Development Officer and the Monitoring Officer. Additional interviews were carried in the field to the farmers. A farmer was interviewed individually followed by farmers in a group. In addition, project documents with valuable information about issues under the study were provided.

Responses were coded, organised and fed into the computer for analysis. The Statistical Package for the Social Sciences (SPSS) was used to analyse the data. The hypothesis was analysed using chi-square test for the relationship between the variables. The hypothesis was rejected or accepted at $\mathrm{p} \leq 0.05$ significant level 


\section{Results and Discussions}

3.1 Conditional credit versus Unconditional credit:

The results of the relationship between conditional credit offering and use of the credit are shown in Tables 1 and 2. From Table 1, it was found out that 184(88.9\%) of the respondents agreed, conditional credit improved effectiveness of credit use, 21(10.1\%) disagreed and 2(1.0\%) were not sure. Thus majority of the respondents agreed that conditional credit would improve effective use of credit. The chi-square test for the relationship between conditional credit and effective use of credit is shown in Tables 2 which was found to be 0.056 . At $p \leq$ 0.05 the relationship was not significant. Thus, There is no significant relationship between conditional credit and effective use of credit.

The results of the relationship between unconditional credit and effective use of credit are shown in Tables 1 and 2. From Table 1, 137(65.2\%) of the respondents agreed that unconditional credit but with strict supervision by the credit agency could lead to effective credit use, 56(26.7\%) disagreed and 17(7.1\%) were not sure. The chisquare test for the relationship between unconditional credit alongside strict supervision and effective use of credit is shown in Table 2 which was found to be 0.005 . At $p<0.05$ the association is significant. Thus, There is a positive relationship between unconditional credit but with strict supervision by the credit agency and effective use of credit. The positive association between unconditional credit alongside strict supervision of credit use may require more investigation However, the more likely causes could be that under this kind of credit arrangement, the credit agency takes an active role in guiding the beneficiary on the use of the credit but guided by the beneficiary's own goals. Diagne (2000), reports in the Malawi Rural Finance Company (MRFC) that close monitoring ensured effective credit use. Supervised credit use alongside the LEW's own objectives may make them feel the concern of the credit agency to improve their lives by effectively filling the financial gap that was perhaps the limitation to realisation of their goals. It could also be partly because this offers a good reason for the LEW to stop their spouses from taking some of the borrowed money or interfering with the projects. Other possible reasons are obedience to the supervisors so as to continue receiving their attention and that supervision is able to offer quick corrective measures where the investment or project could have gone wrong.

\subsection{Credit in-kind versus credit in cash}

The results of relationship between credit in-kind and effective use of credit are shown in Table1 and 2. From Table 1, the following results are shown, 152(73.1\%) of the respondents agreed that credit in-kind would improve effective use of credit, 56(26.7\%) disagreed and $17(8.1 \%)$ were not sure. This indicated that the majority of the respondents shared the view that credit in kind led to effective credit use. The result of chi-square test is shown in Table 2 and was found out to be 0.000 indicating a positive relationship implying credit in-kind is effectively put to effective use by the LEW. Thus, there is a positive relationship for credit in-kind and effective credit use.

\subsection{Relationship between pre-training and effective use of credit:}

The results of relationship between pre-training and effective use of credit are shown in Tables 1 and 2 . From Table 1, the results are that $204(97.6 \%)$ of the respondents agreed that pre-training improves effectiveness of credit use, $4(1.9 \%$ disagreed and $1(0.5 \%)$ was not sure indicating that majority agree that pre-training before the credit offer improves on effective use of credit. The chi-square test for the relationship between pre-training and effectiveness in credit use is shown in Table 2 which was 0.002 . The hypothesis was therefore rejected. Consequently, There is a positive relationship between pre-training and effectiveness of credit use.

Most likely credit services alone particularly to the low income groups such as LEW may not improve their lives because of other factors associated with their situation. They require other complimentary supporting services to improve on the productivity of the credit offered. Pre-training is one of those services required. Zeller and Sharma had similar observations when they observed that, Managers of microfinance institutions in Asia and Africa often find that providing financial services to the poor is not enough to attract the poorest clients because of the many constraints they face. Credit may offer low returns to investment for households especially when they are illiterate or lacking experience in high-yielding agro technology or nonfarm microenterprises (Zeller and Sharma, 1998). Perhaps offering financial services alongside offering appropriate training services is most likely to improve the productivity of the loans provided.

\subsection{Relationship between peer monitoring and effective use}

The results of the relationship between peer monitoring and effective use of the credit are shown in the Tables 1 and Table 2. From Table 1, it was observed, 53(25.4\%) of the respondents agreed that peer monitoring improved effectiveness of credit use, $141(67.5 \%)$ disagreed while $15(7.1 \%)$ were not sure indicating that the majority disagreed. A chi-square test for the association between peer pressure and effective credit use is shown in table which was found to be 0.171 , indicating the relationship is not significant, thus the hypothesis is accepted. Consequently, there is a negative relationship between peer monitoring and response to credit by the LEW. Under Peer Monitoring, members of the group take active role in tracking how their colleagues are using the credit, 
checking on whether the colleagues are using the credit for the purposes it was borrowed for. While most of the LEW supported being in a group when it comes to accessing credit services, they preferred individual credit though with group guarantee. Perhaps there is some level of privacy they preferred when it came to money matters. The investigator's personal experience with people in the study area is that they would be uncomfortable about claims that any of their peers was responsible for their up keep. Perhaps they view peer monitoring as internal interference by the peers in the management of finances at the household level.

Table 1: Factors affecting effective use of credit among the LEW

\begin{tabular}{rrrrr}
\hline Conditions of Credit & & Frequeny & Percent & Valid Percent \\
\hline Conditional credit better used & & & \\
& Agree & 184 & 87.6 & 88.9 \\
& Disagree & 21 & 10.0 & 10.1 \\
Not sure & 2 & 1.0 & 1.0 \\
Total & 207 & 98.6 & 100.0 \\
No response & 3 & 1.4 & \\
Total & 210 & 100.0 & \\
Unconditional credit but with strict & & & \\
supervision is effectively & Ased & & & \\
Agree & 137 & 65.2 & 26.7 \\
Disagree & 56 & 26.7 & 8.1 \\
Not sure & 17 & 8.1 & 100.0
\end{tabular}

Credit in kind would be used more effectively than in cash

$\begin{array}{lcc}\text { Agree } & 152 & 72.4 \\ \text { Disagree } & 53 & 25.2 \\ \text { Not sure } & 3 & 1.4 \\ \text { Total } & 208 & 99.0 \\ \text { No response } & 2 & 1.0 \\ \text { Total } & 210 & 100.0\end{array}$

Pre-training could lead to

Credit being used effectively

Agree

Disagree

Not sure

Total

No response

Total

Peer monitoring could improve efficiency of credit use

$\begin{array}{ll}\text { Agree } & 53 \\ \text { Disagree } & 141\end{array}$

Not sure

Total

$\mathrm{n}=210$ 
Table 2: Summary of the findings for the relationship between various credit arrangements and effective credit use

Indpendent Variable Dependent Variabe Chi-square test (x2)

i) Conditional credit/ credit with Parallel activities

ii) Unconditional credit,strict supervision credit use

iii) Credit in kind

iv) Pre-training to enhance productivity

v) Peer monitoring

Effective use of credit

0.056

Effective use of credit

0.005

Effective use of credit $\quad 0.000$

Effective use of credit

0.002

Effective use of credit $\quad 0.171$ $\mathrm{n}=210, \mathrm{p}<0.05$

\section{Findings and Policy Implications}

i. Unconditional credit alongside strict supervision

The results of the relationship between conditional credit and effective use of credit were found to be 0.056 . At $p$ $\leq 0.05$ the relationship was not significant. Thus, There is no significant relationship between conditional credit and effective use of credit. However, the results of the relationship between unconditional credit and use of credit were found to be 0.005 . At $\mathrm{p} \leq 0.05$ the association is significant. Thus, there is a positive relationship between unconditional credit but with strict supervision by the credit agency and effective use of credit. The positive association between unconditional credit alongside strict supervision of credit use by LEW farmers is most likely be as a result of active role played in guiding the beneficiary on the use of the credit but guided by the beneficiary's own goals. As earlier discussed elsewhere in this paper, supervised credit use most likely minimizes their male spouses from taking some of the borrowed money or interfering with the projects. There could be other possible reasons. Therefore, credit offers to LEW farmers could best be offered alongside strict supervision more so in form of support training. In terms of Agricultural Extension, credit linked extension programmes that address the farmers own goals should be the way forward.

ii. Relationship between pre-training and effective use of credit:

The result of relationship between pre-training and use of credit indicated is a positive relationship between pretraining and effectiveness of credit use. Credit may offer low returns to investment disadvantaged groups such as LEW farmers especially when they are illiterate or lack technical knowhow in aspects farming or any other areas of likely investment. Credit offering alongside appropriate training services is most likely to improve the productivity of the loans provided. In relation to Agricultural Extension, credit for farming whether in cash or inkind should have a strong inbuilt pre-training, credit service and pre-training services should be offered in tandem. Extension agencies have the advantage and capacity to empower the LEW technically in farm matters.

iii. The results of relationship between credit in-kind and credit use was found to be 0.000 indicating a positive relationship implying credit in-kind is put to effective use by the LEW farmers. Thus, there is a positive relationship for credit in-kind and effective credit use. Among the disadvantaged groups, dominance by male spouse on where and how to cash is common. In such situations, it would therefore be most appropriate to offer credit in-kind, in form of materials, farm inputs, implements.

\section{References}

A Guide to Working with Informal Financial Institutions (2014). Retrieved on 20/9/2019, www.technoserve.org. Aredo, D. (1993). The Informal and Semi-Informal Finance Sectors in Ethiopia: A study of the Iqqub, Iddir and Savings and Credit Co-operatives. A E R C Research Paper 21, AERC, Nairobi Kenya.

Aryeetey, E. (1995). Filling the Niche Informal Finance in Africa. African Economic Research consortium (AERC) Nairobi Kenya.

Borg, W.R. and Gall, M.D. (1983). Educational Research, An introduction. New York; Longman.

Casley D.J. \& Lury, D.A (1981). Data collection in Developing countries. New York, Oxford University Press. Cheruiyot, A. and Kioko, K. (1999). Financial Services Associations. Evaluation Report No. 32, K-REP, Nairobi,Kenya.

Esipisu, E., Nasubo, G., Obuya, M., Kioko, K. (1995). Lending through Chikola Groups four years of experience. Evaluation Report No. 28, K-REP, Nairobi, Kenya.

Food and Agricultural Orgaization (FAO), (1997). Participation in Practice/ 4 Forming Groups of the Rural Poor. (Mimeotypescript). Sustainable Development (SD): People, Rome, Italy.

Food and Agricultural Organization (FAO) (1997). Participation in Practice/7. The Financial Component. (Mimeotypescript. Sustanaible Development (SD): People, Rome, Italy. 
Goetz A.M. (1996) Who Takes The Credit: Gender, and Control over Loan Use in Rural Credit Programs in Rural Credit Programmes in Bangladesh. World Development.

Goodluck, C. and Neema, M. (2017). Loan Repayment Performance of Clients of Informal Lending Institutions: Do Borrowing Histories and Dynamic Incentives Matter? The International Journal of Development Issues. Vol.16. No.3. Emerald Publishing Limited.

Government of Kenya (1996). National Development Plan (1997 - 2001).

International Fund for Agricultural Development (IFAD), (2000): Rural Financial Services Project, Pre-Appraisal (IFAD Project Ghana), Rome Italy.

International Labour Organization (ILO), (1972). Employment, Incomes and Equality - A strategy for Increasing Employment in Kenya, Geneva.

Jaetzold, J and Schmidt, H. (1982). Farm Management Handbook of Kenya Vol. II/A, West Kenya, Ministry of Agriculture, Nairobi.

Kathuri, N.J. and Pals D.A. (1993). Introduction to Educational Research. Educational Media Centre (EMC) Egerton University, Njoro, Kenya.

Khandker, S.R. and Khalily, B. (1996). The Bangladesh Rural Advancement: Committee's Credit Programmes Performance and Sustainability. The World Bank, Washington, DC.

Lele Uma, J. (1973). Role of Credit and Marketing Functions in Agricultural Development. Prajnan. (Quarterly, Journal of the National Institute of Bank Management, Bombay.

Ministry of Agriculture and Livestock Development (1997). Divisional Agricultural and Livestock Extension Officer Annual Report, Funyula Division.

Mitchnink D. (1996). Operational Guidelines for Credit Projects (Mimeo typescript).

Mosher, C.A. and Kalton, G. (1971). Survey Methods in Social Investigation. Gower, England.

Nassiuma, D. K. (2000). Survey Sampling: Theory and Methods. Nairobi University, Kenya. Nairobi University Press.

Nisbet, C.T. (1973). Informal Lenders as Suppliers of Development Credits to SmallFarmers in Developing Countries. Attractive or Deceptive Alternative. Evergreen State College, Olypia, Washington.

Pride Africa. Pride Africa at a Glance 4 (mimeo typescript).

Quisumbig, A.R., Brown, L.R., Feldstein, H. S., Haadd, L. and Pena, C. (1995). Women: The Key to Food Security. Food Policy Report, IFPRI, Washington D.C. U.S.A.

Sharma, M. and Zeller, M. (2000). Factors Affecting Repayment Rates in Group-Based Lending: Findings from Bangladesh and Madagascar. Policy Brief No. 9, IFPRI. Washington D.C. USA.

Sharma, M. (2000). Impact of Microfinance on Poverty Alleviation: What Does Emerging Evidence Indicate? Policy Brief No.2, IFPRI, Washington D.C. USA.

Tuckman, B.W. (1978). Conducting Educational Research. Harcourt Brance Jovnonich Inc. New York USA.

Vincent, F. (1995) Alternative Financing of Third World Development Organizations and NGOs. Vol. I Development innovations and Networks (IRED) Geneva, Switzerland.

Zeller, M. and Sharma, M. (1998). Rural Finance and Poverty Alleviation. Food Policy Report, IFPRI, Washington, D.C. USA.

Zeller, M.and Sharma, M (2000). The Demand for Financial Services by the Rural Poor. Policy Brief No. 1, IFPRI Washington D.C. USA. 